\title{
Out-of-hospital cardiac arrest treated by emergency medical service teams during COVID-19 pandemic: A retrospective cohort study
}

\author{
Magdalena J. Borkowska ${ }^{1}$, Jacek Smereka ${ }^{2,3}$, Kamil Safiejko ${ }^{1}$, Klaudiusz Nadolny ${ }^{4,5}$, \\ Maciej Maslanka, ${ }^{3,6}$ Krzysztof J. Filipiak ${ }^{7}$, Milosz J. Jaguszewski ${ }^{8}$, Lukasz Szarpak ${ }^{1,3}$ \\ ${ }^{1}$ Bialystok Oncology Center, Bialystok, Poland \\ ${ }^{2}$ Department of Emergency Medical Service, Wroclaw Medical University, Wroclaw, Poland \\ ${ }^{3}$ Polish Society of Disaster Medicine, Warsaw, Poland \\ ${ }^{4}$ Faculty of Medicine, Katowice School of Technology, Katowice, Poland \\ ${ }^{5}$ Department of Emergency Medical Service, Strategic Planning University of Dabrowa Gornicza, Poland \\ ${ }^{6}$ Maria Sklodowska-Curie Medical Academy in Warsaw, Poland \\ ${ }^{7}$ First Chair and Department of Cardiology, Medical University of Warsaw, Poland \\ ${ }^{8}$ First Department of Cardiology, Medical University of Gdansk, Poland
}

\section{This paper was guest edited by Prof. Togay Evrin}

\begin{abstract}
Background: Out-of-hospital cardiac arrest (OHCA) is a challenge for medical personnel, especially in the current COVID-19 pandemic, where medical personnel should perform resuscitation wearing full personal protective equipment. This study aims were to assess the characteristics and outcomes of adults who suffered an OHCA in the COVID-19 pandemic treated by emergency medical service (EMS) teams. Methods: All EMS-attended OHCA adults over than 18 years in the Polish EMS registry were analyzed. The retrospective EMS database was conducted. EMS interventions performed between March 1, and April 30, 2020 were retrospectively screened.

Results: In the study period EMS operated 527 times for OHCA cases. The average age of patients with $\mathrm{OHCA}$ was 67.8 years. Statistically significantly more frequently men were involved (64.3\%). 298 (56.6\%) of all OHCA patients had resuscitation attempted by EMS providers. Among resuscitated patients, $73.8 \%$ were cardiac etiology. $9.4 \%$ of patients had return of spontaneous circulation, $27.2 \%$ of patients were admitted to hospital with ongoing chest compression. In the case of $63.4 \%$ cardiopulmonary resuscitation was ineffective and death was determined.

Conclusions: The present study found that OHCA incidence rate in the Masovian population (central region of Poland) in March-April 2020 period was 12.2/100,000 adult inhabitants. Return of spontaneous circulation in EMS was observed only in $9.4 \%$ of resuscitated patients. The presence of shockable rhythms was associated with better prognosis. The prehospital mortality, even though it was high, did not differ from those reported by other studies. (Cardiol J 2021; 28, 1: 15-22)
\end{abstract}

Key words: out-of-hospital cardiac arrest, cardiopulmonary resuscitation, return of spontaneous circulation, outcome, COVID-19

Address for correspondence: Lukasz Szarpak, Assoc. Prof. PhD, MBA, Bialystok Oncology Center, ul. Ogrodowa 12, 15-027 Białystok, Poland, tel: +48 500186225, e-mail: lukasz.szarpak@gmail.com

Received: 30.07.2020 Accepted: 2.09.2020

This article is available in open access under Creative Common Attribution-Non-Commercial-No Derivatives 4.0 International (CC BY-NC-ND 4.0) license, allowing to download articles and share them with others as long as they credit the authors and the publisher, but without permission to change them in any way or use them commercially. 


\section{Introduction}

Out-of-hospital cardiac arrest (OHCA) remains a major public health problem [1], especially in the emergency medical service (EMS) teams, where staff, due to limited personnel, are often forced to choose which procedure to follow first [2]. As Gräsner et al. [3] indicates, the prevalence of OHCA is 40 cases per 100,000 adults. For the United States and Canada, this is close to 400,000 OHCA cases per year, respectively [4]. The higher prevalence of OHCA of 170/100,000 is indicated by Gach et al. in their study [5]. Majority of OHCAs occur in adults, with a small proportion occurring in pediatric and young adult populations [6].

The challenges faced by medical staff in terms of OHCA are further hampered by the current COVID-19 pandemic, as every pre-hospital patient should be treated as potentially infected with SARS-CoV-2 until this is ruled out $[7,8]$. Therefore, following the recommendations of the World Health Organization (WHO), medical personnel providing medical assistance to patients with suspected/confirmed COVID-19 should be equipped with full personal protective equipment. This applies in particular to aerosol generating procedures, such as airway management or cardiopulmonary resuscitation (CPR) [9, 10]. In Polish settings, EMS personnel are usually equipped with a full protective suit, a mask with FFP2 or FFP3 class filter, protective glasses, visor and double gloves. This garment reduces the risk of infection but, as numerous studies have shown, makes it difficult to perform medical procedures, including those so important for CPR, such as chest compressions [10], airway management [11, 12], obtaining vascular access $[13,14]$, or the administration of drugs and fluids during resuscitation $[15,16]$.

This study aims were to assess the characteristics and outcomes of adults who suffered an OHCA in the COVID-19 pandemic treated by EMS teams.

\section{Methods}

The study was performed following the ethical standards of the Declaration of Helsinki and approved by the institutional review board of the Polish Society of Disaster Medicine (approval no. 01.06.20.IRB).

\section{Study design}

Emergency medical service teams' medical records were analyzed. The data were obtained concerning the largest voivodeship in Poland -
Masovia Voivodeship. Masovia Voivodeship is the largest voivodeship in Poland both in terms of area and population. It also includes the capital of Poland - Warsaw. The region covers an area of $35,558,47 \mathrm{~km}^{2}$. As of 31 December 2019, there were about 5.4 million inhabitants, including 4.3 million adults (over than 18 years of age). There are 200 ground-based medical rescue teams located in 128 locations in the voivodeship.

The study population consisted of 527 adult OHCA patients for whom EMS teams intervened from March 1, 2020 to April 30, 2020. Data from adult patients aged 18 years or older with OHCA were analyzed (Fig. 1). Clinical diagnosis was based on the International Statistical Classification of Diseases and Related Health Problems classification in revision 10 [17]. All patients included an intention to treatment analysis. Patients were de-identified after data were collected from digital records.

The study cohort were comprised of adult OHCA patients treated by EMS teams during the above specified periods. Demographic data gathered from electronic medical records included gender, age, medical diagnosis and medical procedure.

\section{Outcomes}

Primary outcome of this study was the return of spontaneous circulation (ROSC) in the prehospital period, defined as the steady return of circulation and/or breathing. The etiology of OHCA was categorized as cardiac or noncardiac. Noncardiac causes were subdivided into respiratory disease, stroke, malignant tumor, external causes (e.g., trauma, drowning, burn, asphyxia, or intoxication), or other noncardiac causes. The etiology of OHCA was presumed to be cardiac unless evidence suggested a noncardiac cause [18]. Therefore, the cardiac etiology included confirmed and presumed cases.

\section{Statistical analysis}

Data were analyzed by means of the statistical package STATISTICA 13.3EN (Tibco Inc, Tulusa, OK, USA). Categorical variables were expressed as number and percent. Continuous variables were reported as mean and standard deviation (SD) or median and interquartile range (IQR), depending on the normal distribution of the data. Binary data were compared between the treatment groups using by the $\chi^{2}$ test. Continuous data were compared between groups using the t test. Group differences were calculated, along with their $95 \%$ confidence intervals (CI). The authors focused on compar- 


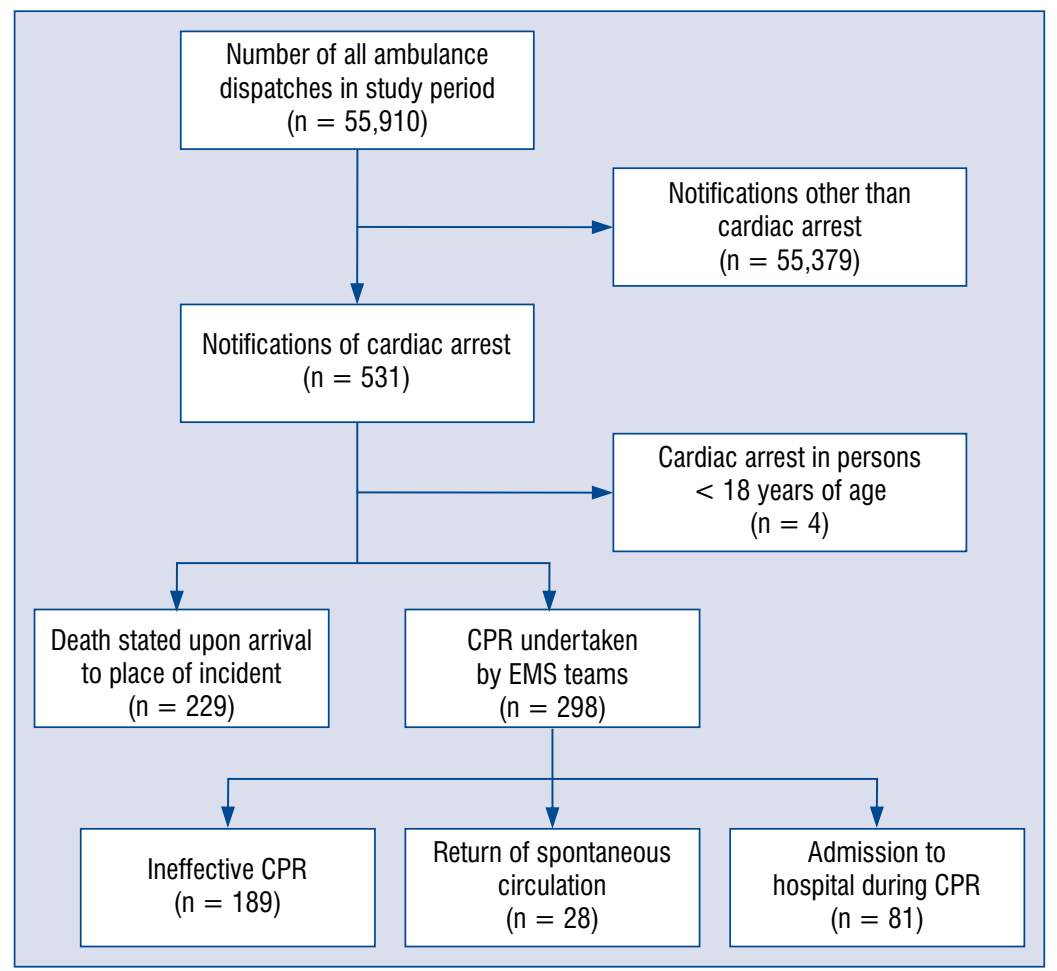

Figure 1. Patients' flow chart; CPR — cardiopulmonary resuscitation; EMS - emergency medical service.

ing means rather than medians, because it was intended to include extreme values in analysis. Thus, the t-test for group comparisons of means was used. A p-value $\leq 0.05$ was considered to indicate statistical significance.

\section{Results}

In the period from March to April 2020, medical emergency teams from the Mazovian region performed 55,910 interventions, of which 527 interventions were carried out on patients with cardiac arrest, which constituted $0.9 \%$ of all intentions in the examined period. CPR was initiated in 298 cases, while in the remaining 229 cases, death before the EMS team had arrived was diagnosed and no resuscitation activities were undertaken (Table 1).

Patients without resuscitation activities where death was diagnosed were statistically significantly older than those in whom CPR activities were undertaken (70.8 vs. 65.4 years, respectively; $\mathrm{p}=0.001)$.

The analysis showed that the time from the call to contact was on average 2 min longer in the case of patients who were found dead without resuscitation (12 vs. $10 \mathrm{~min} ; \mathrm{p}=0.026$, respectively).
On the other hand, there were no significant differences between the groups in terms of etiology of cardiac arrest, the reason reported during the call or rate of resuscitation provided by bystanders (Table 1).

\section{Return of spontaneous circulation analysis}

A detailed distribution of patients in whom CPR was implemented is presented in Table 2 . Due to the resuscitation status, patients were divided into three groups. In 189 cases CPR was ineffective, was discontinued, and the patient was found dead. In 28 cases there were 28 cases of pre-hospital ROSC, while 81 patients were transferred to hospital during CPR. The group of patients with unsuccessful CPR or were found dead had the highest age -67.9 years, compared to those with ROSC -58.3 years, and those transported to hospital with ongoing CPR -62.0 years (Fig. 2).

Resuscitation was usually provided in the morning and the time of day did not significantly affect the effectiveness of resuscitation; similarly, there was no significant correlation between the effectiveness of resuscitation and the institution of resuscitation by witnesses or the presence of medical personnel during cardiac arrest. 
Table 1. Number and Incidence rate of out-of-hospital cardiac arrests in study period.

\begin{tabular}{|c|c|c|c|c|}
\hline Parameter & $\begin{array}{c}\text { Total } \\
(n=527)\end{array}$ & $\begin{array}{c}\text { Resuscitation } \\
\text { has been initiated } \\
(n=298)\end{array}$ & $\begin{array}{l}\text { No resuscitation } \\
\text { was undertaken } \\
\text { (n=229) }\end{array}$ & $\mathbf{P}$ \\
\hline Age, mean (SD) & $67.8(16.2)$ & $65.4(170.2)$ & $70.8(14.4)$ & 0.001 \\
\hline Age of men & $65.0(15.9)$ & $62.4(17.4)$ & $68.3(13.2)$ & $<0.001$ \\
\hline Age of women & $72.7(15.5)$ & $70.7(15.5)$ & $75.3(15.3)$ & $<0.001$ \\
\hline \multicolumn{5}{|l|}{ Sex: } \\
\hline Male (\%) & $339(64.3)$ & $192(64.4)$ & $147(64.2)$ & \multirow[t]{2}{*}{1.0} \\
\hline Female (\%) & $188(25.7)$ & $106(35.6)$ & $82(35.8)$ & \\
\hline Weekday (Monday to Friday) & $381(72.3)$ & $217(72.8)$ & $164(71.6)$ & \multirow[t]{2}{*}{1.0} \\
\hline Weekend (Saturday and Sunday) & $146(27.7)$ & $81(27.2)$ & $65(28.4)$ & \\
\hline Morning (8 am to $4 \mathrm{pm}$ ) & $206(39.1)$ & $120(40.3)$ & $86(37.5)$ & \multirow[t]{3}{*}{0.768} \\
\hline Evening ( $4 \mathrm{pm}$ to $11 \mathrm{pm})$ & $176(33.4)$ & 95 (31.9) & $81(35.4)$ & \\
\hline Night (11 pm to $8 \mathrm{am})$ & $145(27.5)$ & $83(27.8)$ & $62(27.1)$ & \\
\hline Time from call to contact with patient, min & $11.1(7.0)$ & $10.0(5.9)$ & $12.0(8.2)$ & 0.026 \\
\hline Time from call to hospital arrival, min & $46.0(27.3)$ & $45.4(27.8)$ & & \\
\hline Time from contact with patient to hospital arrival & $57.5(28.6)$ & $57.3(29.2)$ & & \\
\hline \multicolumn{5}{|l|}{ Cardiac arrest etiology: } \\
\hline Cardiac & 379 (71.9) & $220(73.8)$ & $159(69.4)$ & \multirow[t]{2}{*}{0.387} \\
\hline Non-cardiac & $148(28.1)$ & $78(26.2)$ & $70(30.6)$ & \\
\hline Bystander CPR & $53(10.1)$ & $37(12.4)$ & $16(10.0)$ & 1.0 \\
\hline SCA in the presence of EMS & $25(4.7)$ & $20(6.7)$ & $5(2.2)$ & 1.0 \\
\hline \multicolumn{5}{|l|}{ The reason for the call EMS } \\
\hline Sudden cardiac arrest & $134(25.4)$ & $81(27.2)$ & $53(23.1)$ & \multirow[t]{10}{*}{0.091} \\
\hline Unconscious & $154(29.2)$ & $89(29.9)$ & $65(28.4)$ & \\
\hline Syncope & $68(12.9)$ & $37(12.4)$ & $31(13.5)$ & \\
\hline Chest pain & $9(1.7)$ & $9(3.0)$ & $0(0.0)$ & \\
\hline Dyspnoea & $67(12.7)$ & $33(11.1)$ & $34(14.8)$ & \\
\hline Convulsions & $13(2.5)$ & $9(3.0)$ & $4(1.7)$ & \\
\hline Choking & $5(0.9)$ & $2(0.7)$ & $3(1.3)$ & \\
\hline Hemorrhage, bleeding & $3(0.6)$ & $2(0.7)$ & $7(0.4)$ & \\
\hline Injury & $3(0.6)$ & $3(1.0)$ & $0(0.0)$ & \\
\hline Others & $71(13.7)$ & $33(11.1)$ & $38(16.6)$ & \\
\hline \multicolumn{5}{|l|}{ Initial heart rhythm } \\
\hline Asystole & 400 (75.9) & $171(57.4)$ & $229(100.0)$ & \multirow[t]{3}{*}{$<0.001$} \\
\hline PEA & $62(11.8)$ & $62(20.8)$ & $0(0.0)$ & \\
\hline $\mathrm{VF} / \mathrm{pVT}$ & $65(12.3)$ & 65 (21.8) & $0(0.0)$ & \\
\hline
\end{tabular}

CPR — cardiopulmonary resuscitation; EMS — emergency medical service; NS — not statistically significant; PEA — pulseless electrical activity; pVT - pulseless ventricular tachycardia; SCA — sudden cardiac arrest; SD — standard deviation; VF — ventricular fibrillation

Statistical analysis showed that the first electrocardiogram rhythm observed by medical personnel was significant in terms of CPR effectiveness and follow-up $(\mathrm{p}=0.026$; Table 2$)$.

\section{Discussion}

The aim of this study was perform an epidemiological analysis of OHCA during the imple- 
Table 2. Demographic findings according to the relationship between the effectiveness of resuscitation.

\begin{tabular}{|c|c|c|c|c|c|}
\hline Parameter & $\begin{array}{c}(A) \\
\text { Died on scene } \\
(n=189)\end{array}$ & $\begin{array}{c}(B) \\
\text { ROSC } \\
(n=28)\end{array}$ & $\begin{array}{c}\text { (C) } \\
\text { Admission } \\
\text { under CPR } \\
(\mathrm{n}=\mathbf{8 1})\end{array}$ & P-value & $\mathbf{P}$ \\
\hline Age, mena (SD) & $67.9(16.7)$ & $58.3(20.7)$ & $62.0(15.9)$ & $\begin{array}{c}\text { A vs. } B=0.028 \\
\text { A vs. } C=0.007 \\
\text { Other }=N S\end{array}$ & 0.002 \\
\hline Age of men & $65.5(16.7)$ & $54.6(20.2)$ & $56.3(18.5)$ & $\begin{array}{c}\text { A vs. } B=0.007 \\
\text { A vs. } C=0.016 \\
\text { Other }=N S\end{array}$ & $<0.001$ \\
\hline Age of women & $72.1(72.3)$ & $66.1(20.4)$ & $70.2(17.4)$ & $\begin{array}{c}\text { A vs. } B=0.001 \\
\text { A vs. } C=0.023 \\
\text { Other }=N S\end{array}$ & $<0.001$ \\
\hline \multicolumn{6}{|l|}{ Sex: } \\
\hline Male (\%) & $120(63.5)$ & 19 (67.9) & $53(65.4)$ & NS & 1.0 \\
\hline Female (\%) & $69(36.5)$ & $9(32.1)$ & $28(24.6)$ & & \\
\hline Weekday (Monday to Friday) & $138(73.0)$ & $18(64.3)$ & $61(75.3)$ & NS & 1.0 \\
\hline Weekend (Saturday and Sunday) & $51(27.0)$ & $10(35.7)$ & $20(24.7)$ & NS & \\
\hline Morning (8 am to $4 \mathrm{pm}$ ) & $77(40.7)$ & $9(32.1)$ & $34(42.0)$ & NS & 0.460 \\
\hline Evening (4 am to $11 \mathrm{pm}$ ) & $57(30.2)$ & $14(50.0)$ & $24(29.6)$ & NS & \\
\hline Night (11 pm to $8 \mathrm{am})$ & $55(29.1)$ & $5(17.9)$ & $23(28.4)$ & NS & \\
\hline Time from call to contact with patient, min & $10.8(5.9)$ & $10.0(5.9)$ & $9.4(5.8)$ & NS & 0.427 \\
\hline Time from call to hospital arrival, min & & $43.6(18.9)$ & $42.5(24.0)$ & NS & 0.347 \\
\hline Time from contact with patient to hospital a & arrival & $54.6(21.4)$ & $53.4(24.1)$ & NS & 0.249 \\
\hline \multicolumn{6}{|l|}{ Cardiac arrest etiology } \\
\hline Cardiac & $142(75.1)$ & $18(64.3)$ & $60(74.1)$ & NS & 1.0 \\
\hline Non-cardiac & $47(24.9)$ & $10(35.7)$ & $21(25.9)$ & & \\
\hline Bystander CPR & $23(12.2)$ & $7(25.0)$ & $7(8.6)$ & NS & 1.0 \\
\hline SCA in the presence of EMS & $12(6.3)$ & $2(7.1)$ & $6(7.4)$ & NS & 1.0 \\
\hline \multicolumn{6}{|l|}{ The reason for the call EMS } \\
\hline Sudden cardiac arrest & $57(30.2)$ & $6(21.4)$ & $18(22.2)$ & NS & 0.650 \\
\hline Unconscious & $54(28.6)$ & $8(28.6)$ & $27(33.3)$ & & \\
\hline Syncope & $23(12.2)$ & $3(10.7)$ & $11(13.6)$ & & \\
\hline Chest pain & $6(3.2)$ & $0(0.0)$ & $3(3.7)$ & & \\
\hline Dyspnoea & $21(11.1)$ & $4(14.3)$ & $8(10.0)$ & & \\
\hline Convulsions & $4(2.1)$ & $3(10.7)$ & $2(2.5)$ & & \\
\hline Choking & $2(1.1)$ & $0(0.0)$ & $1(1.2)$ & & \\
\hline Hemorrhage, bleeding & $1(0.5)$ & $0(0.0)$ & $0(0.0)$ & & \\
\hline Injury & $3(1.6)$ & $0(0.0)$ & $0(0.0)$ & & \\
\hline Others & $18(9.5)$ & $4(14.3)$ & $11(13.6)$ & & \\
\hline \multicolumn{6}{|l|}{ Initial heart rhythm } \\
\hline Asystole & $119(63.0)$ & $15(53.6)$ & $37(45.7)$ & $\begin{array}{c}\text { A vs. } C=0.031 \\
\text { Other }=\mathrm{NS}\end{array}$ & 0.026 \\
\hline PEA & $39(20.6)$ & $4(14.3)$ & $19(23.4)$ & $\begin{array}{c}\text { A vs. } B=0.034 \\
B \text { vs. } C=0.019 \\
\text { Other }=N S\end{array}$ & \\
\hline $\mathrm{VF} / \mathrm{pVT}$ & $31(16.4)$ & $9(32.1)$ & $25(30.9)$ & $\begin{array}{c}\text { A vs. } B=0.003 \\
\text { A vs. } C=0.005 \\
\text { Other }=N S\end{array}$ & \\
\hline
\end{tabular}

CPR - cardiopulmonary resuscitation; EMS - emergency medical service; NS — not statistically significant; PEA — pulseless electrical activity; pVT — pulseless ventricular tachycardia; SCA — sudden cardiac arrest; VF — ventricular fibrillation 


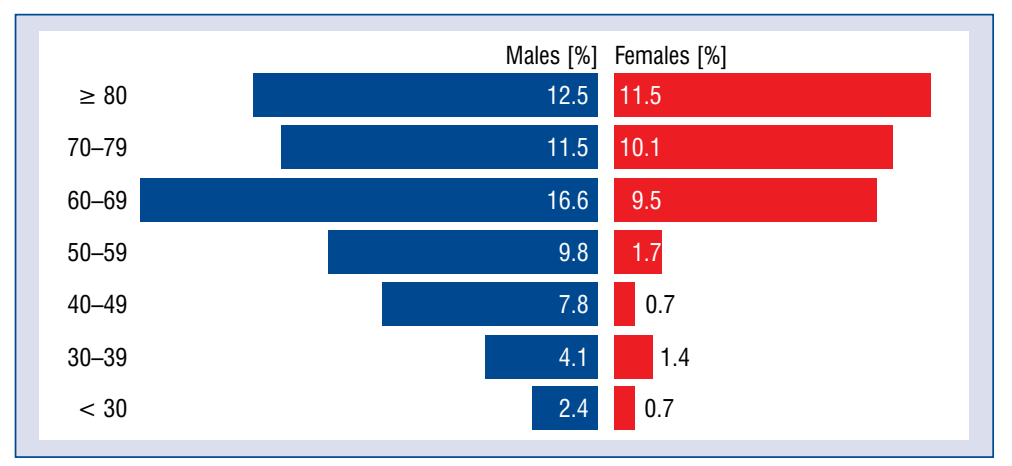

Figure 2. Patient status according to the age.

mentation of restrictions related to the COVID-19 pandemic. According to available research, this is one of the first studies of this type showing the effectiveness of pre-hospital resuscitation during a pandemic, where medical personnel should be dressed in full personal protective equipment and perform all resuscitation activities.

The analysis of the study material showed that 527 patients had OHCA, with only 298 (56.5\%) cases of CPR. The remaining patients showed obvious signs of death and died without CPR. Baldi et al. [19] indicates that in the case of Italy, resuscitation was undertaken in $63.5 \%$ of patients, while in the same period of 2019 - the percentage of resuscitation undertaken was less than $6 \%$ higher.

The mean age of patients with OHCA in the study material was 67.8 years (and 65.4 years for patients on whom CPR was initiated). The age of patients with OHCA in other studies referring to OHCA in COVID-19 outbreak was higher, ranging from 69.7 (17) to 76.3 (2.8) years [19-21]. In the present study, it was also found that men with OHCA were significantly younger than women.

As shown by Baldi et al. [19] the cumulative incidence of OHCA in 2020 was strongly associated with the cumulative incidence of COVID-19 [19, 21]. Baldi et al. [19] compared OHCA that occurred in the provinces of Lodi, Cremona, Pavia, and Mantua during the first 40 days of the COVID-19 outbreak (February 21 through March 31, 2020) with those that occurred during the same period in 2019 and indicate a $58 \%$ increase in the rate of OHCA in 2020.

In the current study, cardiac arrest was much more common in men, who accounted for $64.4 \%$ of all OHCAs, and $64.4 \%$ of cases where resuscitation was undertaken. The higher incidence of OHCA in men is also confirmed by other studies [19].
Besides, a study by Baldi et al. [19] which showed an over 5\% increase in OHCA prevalence in 2020 compared to 2019 (respectively: $65.5 \%$ vs. $60.3 \%$ ). Baldi et al. [19] also indicates that only $7.8 \%$ of patients were transported with ROSC and 10\% with ongoing CPR. In the present study, ROSC was obtained in $9.4 \%$ of cases where resuscitation was undertaken and in $27.2 \%$ of patients who were transported to hospital with ongoing CPR. In the corresponding period of 2019 , it was $19.5 \%$ for ROSC and $13.2 \%$ for transport with ongoing CPR respectively. Pranata et al. [22] suggest that the COVID-19 pandemic was associated with higher OHCA-related mortality. The numbers might be even higher in developing countries due to poor healthcare and emergency medical service systems [22]. In turn Bhatla et al. [23] indicated that cardiac arrests and arrhythmias are likely the consequence of systemic illness and not solely the direct effects of COVID-19 infection.

An important parameter affecting the effectiveness of CPR is the type of the initially observed rhythm. The study showed that the greatest influence on the ROSC concerning ineffective resuscitation was observed when ventricular fibrillation or pulseless ventricular tachycardia was observed as the first monitored cardiac arrest rhythm (odds ratio $=0.43 ; 95 \%$ CI $0.18-1.04)$. This is also confirmed by numerous studies [24, 25].

The CPR literature lacks consensus among the authors on the impact of witnessed CPR on the outcomes of OHCA. Shimamoto et al. [26] indicated that in nursing homes, bystander CPR was not associated with improved outcomes of OHCA. This is also confirmed by Lukić et al. [27]. In turn Goto et al. [28] show that dispatcher-assisted bystander child CPR was associated with improved 1-month favorable neurological outcomes. Analysis herein, shows that the bystander CPR 
was implemented in $10.1 \%$ of all OHCAs, and in $12.4 \%$ of OHCA cases where the EMS team undertook resuscitation, but in none of these cases did it show a significant correlation with ROSC. However, having said this, it should be noted that this data was derived from medical records and a description of the dispatcher's call and does not always take this aspect of previous CPR into account, hence it should be assumed that this result is underestimated.

\section{Limitations of the study}

This recent study has potential limitations. The first limitation is the fact that the study concerned only patients with OHCA from the Masovia Voivodeship in March and April 2020. This period was chosen deliberately, because then restrictions related to COVID-19 started to be introduced and according to WHO medical personnel should use full personal protective equipment during CPR. Another limitation is the outcome was monitored only at the pre-hospital stage; however, such knowledge also allows a determination the effectiveness of CPR and to indicate the problem of emergency calls coming too late for medical rescue teams.

\section{Conclusions}

The present study found that OHCA incidence rate in the Masovian population (central region of Poland) during the March-April 2020 period was $12.2 / 100,000$ adult inhabitants. ROSC in EMS was observed only in $9.4 \%$ of resuscitated patients. The presence of shockable rhythms was associated with better prognosis. The prehospital mortality, even though it was high, did not differ from those reported by other studies.

\section{Acknowledgements}

The authors would like to thank all paramedics who participated in this study. The study was supported by the ERC Research Net and by the Polish Society of Disaster Medicine.

\section{Conflict of interest: None declared}

\section{References}

1. Ong ME, Perkins GD, Cariou A. Out-of-hospital cardiac arrest: prehospital management. Lancet. 2018; 391(10124): 980-988, doi: 10.1016/S0140-6736(18)30316-7, indexed in Pubmed: 29536862.
2. Malysz M, Kacprzak P. Is low voltage ventricular fibrillation still a diagnostic problem? Disaster Emerg Med J. 2019; 4(1): 31-32, doi: 10.5603/demj.2019.0007.

3. Gräsner JT, Bossaert L. Epidemiology and management of cardiac arrest: what registries are revealing. Best Pract Res Clin Anaesthesiol. 2013; 27(3): 293-306, doi: 10.1016/j.bpa.2013.07.008, indexed in Pubmed: 24054508.

4. Mozaffarian D, Benjamin EJ, Go AS, et al. Heart Disease and Stroke Statistics-2016 Update: A Report From the American Heart Association. Circulation. 2016; 133(4): e38-360, doi: 10.1161/CIR.0000000000000350, indexed in Pubmed: 26673558.

5. Gach D, Nowak JU, Krzych EJ. Epidemiology of out-of-hospital cardiac arrest in the Bielsko-Biala district: a 12-month analysis. Kardiol Pol. 2016; 74(10): 1180-1187, doi: 10.5603/ KP.a2016.0086, indexed in Pubmed: 27221961.

6. Zipes DP, Wellens HJ. Sudden cardiac death. Circulation. 1998; 98: 2334-2351.

7. Smereka J, Szarpak L. The use of personal protective equipment in the COVID-19 pandemic era. Am J Emerg Med. 2020; 38(7): 1529-1530, doi: 10.1016/j.ajem.2020.04.028, indexed in Pubmed: 32305157.

8. Smereka J, Szarpak L, Filipiak K. Modern medicine in COVID-19 era. Disaster Emerg Med J. 2020; 5(2): 103-105, doi: 10.5603/ demj.a2020.0012.

9. Szarpak L, Ruetzler K, Dabrowski M, et al. Dilemmas in resuscitation of COVID-19 patients based on current evidence. Cardiol J. 2020; 27(3): 327-328, doi: 10.5603/CJ.a2020.0066, indexed in Pubmed: 32419130.

10. Ruetzler K, Smereka J, Ludwin K, et al. Respiratory protection among healthcare workers during cardiopulmonary resuscitation in COVID-19 patients. Am J Emerg Med. 2020 [Epub ahead of print], doi: 10.1016/j.ajem.2020.05.014, indexed in Pubmed: 32444293.

11. Malysz M, Dabrowski M, Böttiger BW, et al. Resuscitation of the patient with suspected/confirmed COVID-19 when wearing personal protective equipment: A randomized multicenter crossover simulation trial. Cardiol J. 2020; 27(5): 497-506, doi: 10.5603/ CJ.a2020.0068, indexed in Pubmed: 32419128.

12. Koo A, Walsh R, Knutson T, et al. Comparison of intubation using personal protective equipment and standard uniform in simulated cadaveric models. Mil Med. 2018; 183(suppl_1): 216-218, doi: 10.1093/milmed/usx215, indexed in Pubmed: 29635606.

13. Taylor SR, Pitzer M, Goldman G, et al. Comparison of intubation devices in level $\mathrm{C}$ personal protective equipment: A cadaveric study. Am J Emerg Med. 2018; 36(6): 922-925, doi: 10.1016/j. ajem.2017.10.047, indexed in Pubmed: 29074070.

14. Suyama J, Knutsen CC, Northington WE, et al. IO versus IV access while wearing personal protective equipment in a HazMat scenario. Prehosp Emerg Care. 2007; 11(4): 467-472, doi: 10.1080/10903120701536982, indexed in Pubmed: 17907035.

15. Smereka J, Szarpak L, Filipiak KJ, et al. Which intravascular access should we use in patients with suspected/confirmed COVID-19? Resuscitation. 2020; 151: 8-9, doi: 10.1016/j.resuscitation.2020.04.014, indexed in Pubmed: 32304800.

16. Dzieciatkowski T, Szarpak L, Filipiak KJ, et al. COVID-19 challenge for modern medicine. Cardiol J. 2020; 27(2): 175-183, doi: 10.5603/CJ.a2020.0055, indexed in Pubmed: 32286679.

17. Ruetzler K, Szarpak L, Filipiak K, et al. The COVID-19 pandemic - a view of the current state of the problem. Disaster Emerg Med J. 2020; 5(2): 106-107, doi: 10.5603/demj.a2020.0015. 
18. Jacobs I, Nadkarni V, Bahr J, et al. International Liaison Committee on Resuscitation, American Heart Association, European Resuscitation Council, Australian Resuscitation Council, New Zealand Resuscitation Council, Heart and Stroke Foundation of Canada, InterAmerican Heart Foundation, Resuscitation Councils of Southern Africa, ILCOR Task Force on Cardiac Arrest and Cardiopulmonary Resuscitation Outcomes. Cardiac arrest and cardiopulmonary resuscitation outcome reports: update and simplification of the Utstein templates for resuscitation registries: a statement for healthcare professionals from a task force of the International Liaison Committee on Resuscitation (American Heart Association, European Resuscitation Council, Australian Resuscitation Council, New Zealand Resuscitation Council, Heart and Stroke Foundation of Canada, InterAmerican Heart Foundation, Resuscitation Councils of Southern Africa). Circulation. 2004; 110(21): 3385-3397, doi: 10.1161/01. CIR.0000147236.85306.15, indexed in Pubmed: 15557386.

19. Baldi E, Sechi GM, Mare C, et al. Out-of-hospital cardiac arrest during the COVID-19 outbreak in Italy. N Engl J Med. 2020; 383(5): 496-498, doi: 10.1056/NEJMc2010418, indexed in Pubmed: 32348640.

20. Shao F, Xu S, Ma X, et al. In-hospital cardiac arrest outcomes among patients with COVID-19 pneumonia in Wuhan, China. Resuscitation. 2020; 151: 18-23, doi: 10.1016/j.resuscitation.2020.04.005, indexed in Pubmed: 32283117.

21. Marijon E, Karam N, Jost D, et al. Out-of-hospital cardiac arrest during the COVID-19 pandemic in Paris, France: a populationbased, observational study. Lancet Public Health. 2020; 5(8): e437-e443, doi: 10.1016/S2468-2667(20)30117-1, indexed in Pubmed: 32473113.

22. Pranata R, Lim MA, Yonas E, et al. Out-of-hospital cardiac arrest prognosis during the COVID-19 pandemic. Intern Emerg Med.
2020; 15(5): 875-877, doi: 10.1007/s11739-020-02428-7, indexed in Pubmed: 32647947.

23. Bhatla A, Mayer MM, Adusumalli S, et al. COVID-19 and cardiac arrhythmias. Heart Rhythm. 2020; 17(9): 1439-1444, doi: 10.1016/j.hrthm.2020.06.016, indexed in Pubmed: 32585191.

24. Wibrandt I, Norsted K, Schmidt H, et al. Predictors for outcome among cardiac arrest patients: the importance of initial cardiac arrest rhythm versus time to return of spontaneous circulation, a retrospective cohort study. BMC Emerg Med. 2015; 15: 3, doi: 10.1186/s12873-015-0028-3, indexed in Pubmed: 25648841.

25. Sasson C, Rogers MAM, Dahl J, et al. Predictors of survival from out-of-hospital cardiac arrest: a systematic review and meta-analysis. Circ Cardiovasc Qual Outcomes. 2010; 3(1): 63-81, doi: 10.1161/ CIRCOUTCOMES.109.889576, indexed in Pubmed: 20123673.

26. Shimamoto T, Kiyohara K, Matsuyama T, et al. Impact of bystander cardiopulmonary resuscitation and dispatcher assistance on survival after out-of-hospital cardiac arrest among adult patients by location of arrest. Int Heart J. 2020; 61(1): 46-53, doi: 10.1536/ihj.19-301, indexed in Pubmed: 31956145.

27. Lukić A, Lulić I, Lulić D, et al. Analysis of out-of-hospital cardiac arrest in Croatia - survival, bystander cardiopulmonary resuscitation, and impact of physician's experience on cardiac arrest management: a single center observational study. Croat Med J. 2016; 57(6): 591-600, doi: 10.3325/cmj.2016.57.591, indexed in Pubmed: 28051284.

28. Goto Y, Maeda T, Goto Y. Impact of dispatcher-assisted bystander cardiopulmonary resuscitation on neurological outcomes in children with out-of-hospital cardiac arrests: a prospective, nationwide, population-based cohort study. J Am Heart Assoc. 2014; 3(3): e000499, doi: 10.1161/JAHA.113.000499, indexed in Pubmed: 24785780 . 